\title{
Simple criteria to determine detachment point of towed satellite tags provide first evidence of return migrations of whale sharks (Rhincodon typus) at the Galapagos Islands, Ecuador
}

Alex R Hearn ${ }^{1,4^{*}}$, Jonathan R Green ${ }^{2}$, Eduardo Espinoza ${ }^{3}$, Cesar Peñaherrera ${ }^{2}$, David Acuña ${ }^{2}$ and A Peter Klimley ${ }^{1}$

\begin{abstract}
Background: Attachment of towed, floating satellite tags to large marine organisms has provided scientists with a wealth of information on the movements of these species. These tags generally are not programmed to detach at a particular time, yet are often prone to detachment by natural means after only a few days or weeks. It is important to be able to distinguish between the tracks provided by a detached, floating tag, and one that is attached to the subject. To this end, we placed three SPOT-5 and one SPLASH tag on large female whale sharks at Darwin Island (Galapagos Islands), and compared their tracks with those of two floating SPOT-5 tags released at the same site. We present a set of criteria to determine whether a towed satellite tag encased in a float is still attached to the study organism.
\end{abstract}

Results: None of the whale sharks remained in the vicinity of the island. Three of the tracks lasted 31 to 48 days, yet one shark was tracked for 167 days. This was the first recorded bona fide homing migration of a whale shark, travelling $1,650 \mathrm{~km}$ west then returning to Darwin four months later. Two other sharks also returned to Darwin. We found that at the time of detachment, a clear change in the daily timing and quality of transmissions became evident. This, in conjunction with daily depth and temperature summaries, and knowledge of currents and the biology of the subject, can be used to justify endpoints on tracks that continue to accrue positions as the tag floats with the currents.

Conclusions: The data provided by floating tags is sufficiently distinct to be able to determine a detachment date. After detachment, daily transmissions are received in the first hours of the day after midnight (Coordinated Universal Time), the location quality of the transmissions is consistently high, and temperature or depth summaries are consistent with surface records. Prior knowledge of subject behavior and general ocean circulation patterns in the region reinforces the ability to determine detachment date. In some cases, after a prolonged period of more than three or four weeks, the detection pattern may change, yet caution should be exercised in assuming that the tag is, after all, still attached.

Keywords: Galapagos Islands, Migration, SPLASH tag, SPOT tag, Tag detachment, Whale shark

\footnotetext{
* Correspondence: alex@tirn.net

'Department Wildlife, Fish \& Conservation Biology, University of California

Davis, One Shields Avenue, Davis, CA 95616, USA

${ }^{4}$ Turtle Island Restoration Network, 9255 Sir Francis Drake Boulevard,

Olema, CA 94950, USA

Full list of author information is available at the end of the article
} 


\section{Background}

The use of satellite transmitters (or tags) to track the movements of large marine organisms across the oceans has become a common tool across a range of disciplines over the last two decades (see reviews; [1-3]). These tags commonly use the Argos low polar orbit satellite system [4], which uses the Doppler effect on transmission frequency to estimate positions, when the tag is at the surface and a satellite is overhead. For large, free-swimming species, it is often appropriate to place the tag in a torpedo-shaped float, and attach it to the subject by means of a dart and a tether of varying length. Eventually, the tag is likely shed, and may spend an indeterminate period floating at the surface, transmitting data to the satellite system. It is important to be able to distinguish between a tag that is attached to the subject and one that has detached and is floating. This issue has rarely been addressed in the literature (although see [5]) and may lead to debatable tracks - the longest recorded track of a whale shark, travelling $13,000 \mathrm{~km}$ from the Gulf of California across the Pacific [6], has been questioned recently [7] due to the distance of around 10,000 km between the main portion of the track and the last few data points. In addition, floating tags may in some cases provide us with some information about the behavior of the focal species. For example, a floating tag was used to show by comparison the highly oriented movements made by scalloped hammerhead sharks, Sphyrna lewini, at seamounts in Baja California, Mexico [8].

Smart positioning tags (also known as SPOT tags) are programmed to transmit near-real-time positions when the study organisms are at the surface. They may also transmit limited temperature information, in the form of the percent time spent at user-specified temperature bins. A variation of these, known as SPLASH tags, also provide similar summaries of time at depth. SPOT and SPLASH tags come in several forms, depending on the focal species. The towed, floating arrangement has been used to track basking sharks, Cetorhinus maximus, off the British Isles [5]; to describe the movements of whale sharks, Rhincodon typus, in the Gulf of California [6]; to compare the movements of tarpon, Megalops atlanticus, with their bull shark, Carcharhinus leucas, predators in southern Florida [9]; and manta rays, Manta birostris, to determine their association with seasonal oceanographic features off the Yucatan Peninsula, Mexico [10]. Yet the greatest number of individuals tagged and tracked over the widest geographic range are whale sharks [7].

Whale sharks are the world's largest fish, reaching maximum reported lengths of $20 \mathrm{~m}$ [11], and are known to spend significant periods of time at or close to the surface $[12,13]$. They therefore make a good model species for the exploration of tag detachment issues. Predictable seasonal aggregations of whale sharks, often related to feeding, have been reported at certain locations, including Ningaloo Reef, Western Australia; Gladden Spit, Belize; Baja California, Mexico; Holbox Island off the Yucatan Peninsula, Mexico; and the Maldives [14-16]. All these aggregations are made up predominantly of males, and most individuals were below $10 \mathrm{~m}$ in length [7,17-19]. Whale sharks are known to move large distances [20] and their movements or presence at some sites have been linked with oceanographic features [20,21]. However, true migration, implying the movement away from a location over a long distance and a subsequent return, has not been registered to date [22], although photo identification studies have shown that individuals persist at sites over extended periods [23].

Here, we present tracks from an ongoing study to determine the movement patterns of mostly large, female whale sharks that occur seasonally at the Galapagos Islands, Ecuador [24]. By comparison with data from tags deployed directly into the water, we explore how the timing and quality of the transmissions, the depth and temperature data, and the tracks themselves can help us to determine whether and when a tag has detached from the subject organism.

\section{Results}

We tracked six tags, two 'floaters' deployed directly into the ocean and four placed on female whale sharks. Three of these were at least $9 \mathrm{~m}$ in total length $(9 \mathrm{~m}, 10 \mathrm{~m}$ and $11 \mathrm{~m}$ ) and apparently pregnant, given their distended bellies (Figure 1). The fourth was a smaller $5.6 \mathrm{~m}$ immature female. The two additional satellite tags were dropped in the water so that they floated at the surface at the dive site. Three of the shark tracks lasted approximately one month before detachment, while the fourth track lasted 167 days (Table 1). All tags continued to transmit after the estimated date of detachment. We received data from the two floater tags for at least three months.

None of the tagged whale sharks remained in the vicinity of Darwin Island. Each moved in different directions (Figure 2). The longest track was obtained from

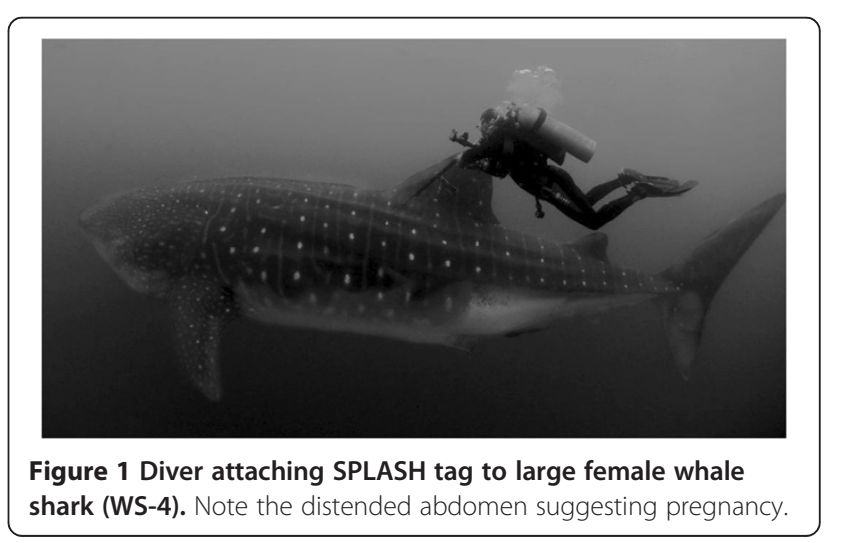


Table 1 Summary of whale shark tracks

\begin{tabular}{|c|c|c|c|c|}
\hline Shark identification & WS-1 & WS-2 & WS-3 & WS-4 \\
\hline Date tagged & 8 July 20111 & 8 September 2011 & 5 September 2012 & 6 September 2012 \\
\hline Estimated total length $(\mathrm{m})$ & 9.0 & 10.0 & 5.6 & 11.2 \\
\hline Track length (days) & 167 & 38 & 31 & 48 \\
\hline Tag type & SPOT-5 & SPOT-5 & SPOT-5 & SPLASH \\
\hline Criteria (ranked) & \multicolumn{4}{|c|}{ Estimated detachment date } \\
\hline 1. Transmission times & 24 December 2011 & 16 October 2011 & 7 October 2012 & 25 October 2012 \\
\hline 2. Transmission qualities & 24 December 2011 & 15 October 2011 & 6 October 2012 & 23 October 2012 \\
\hline 3. Depth/temperature & unclear & 15 October 2011 & 6 October 2012 & 13 October 2012 \\
\hline 4. Tracks & 24 December 2011 & 15 October 2011 & 6 October 2012 & 23 October 2012 \\
\hline
\end{tabular}

All sharks were female. Track lengths (number of days from tagging to last known detection while still attached) estimated using criteria ranked in importance below. Tags continued to transmit while floating, beyond the length of the shark track.

the $9 \mathrm{~m}$ female (WS-1). This shark moved in a westerly direction during the first month of the track (July 2011), reaching a maximum distance of $1,650 \mathrm{~km}$ from Darwin Island. It then circled north and returned towards Darwin, coming within $75 \mathrm{~km}$ of the island on 16 October
2011, before moving further east then south, possibly through the main archipelago, for a further $900 \mathrm{~km}$ on 16 November 2011. The tag did not transmit again until 24 December 2011, when it surfaced approximately $200 \mathrm{~km}$ off the coast of northern Peru, then appeared to

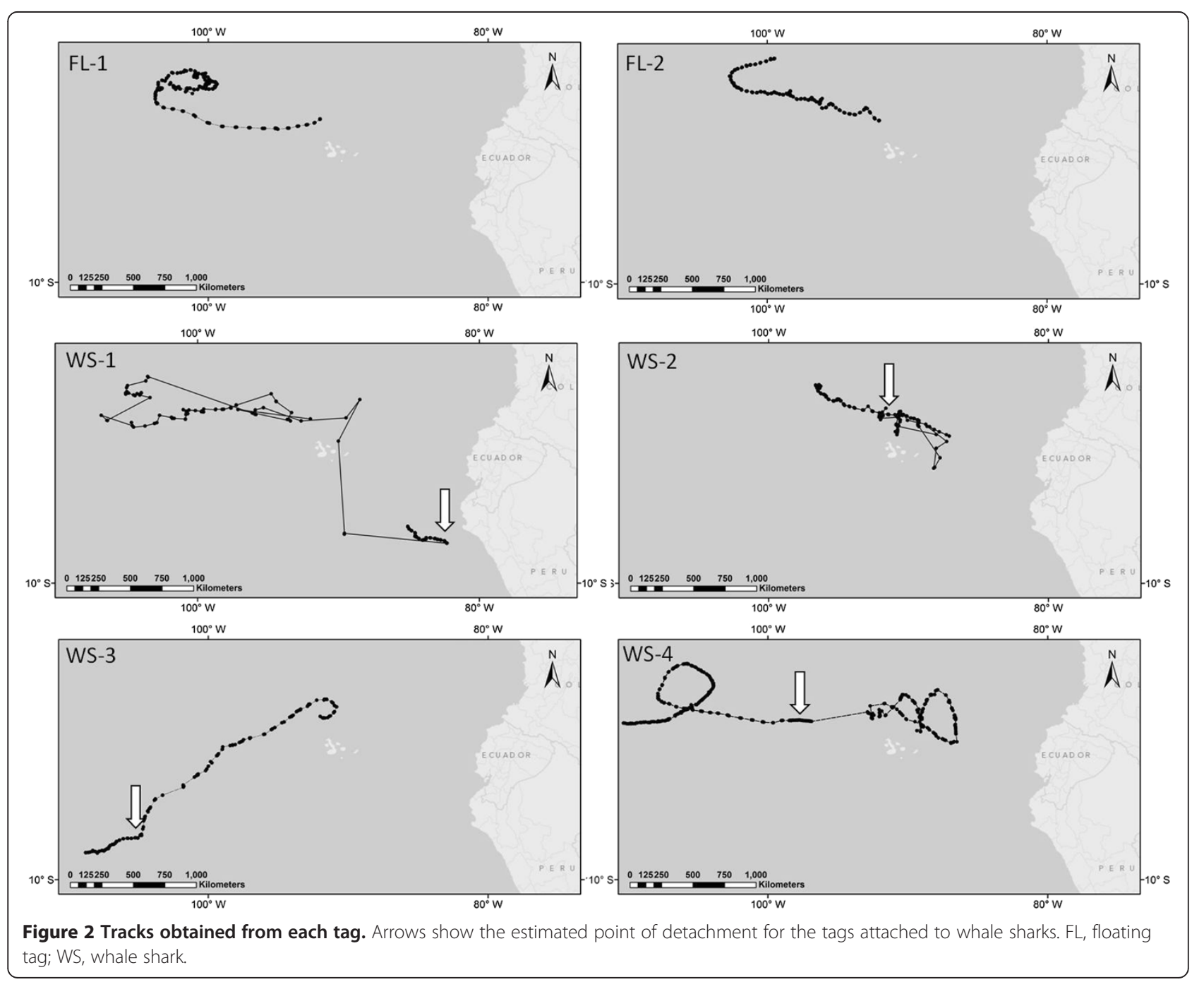


detach and drift north along the shelf break. The cumulative distance travelled over the 167 day track was approximately $6,840 \mathrm{~km}$, averaging an overall movement rate of $41 \mathrm{~km} / \mathrm{d}$ (or $0.47 \mathrm{~m} / \mathrm{s}$ ).

The $10 \mathrm{~m}$ female (WS-2) initially moved $100 \mathrm{~km}$ to the northeast, but returned to within $30 \mathrm{~km}$ of Darwin a week after the tag was attached. The tag detached about $300 \mathrm{~km}$ to the east of Darwin, although the cumulative distance travelled by the shark during the track was $1,044 \mathrm{~km}$.

The smallest whale shark (WS-3, $5.9 \mathrm{~m}$ ) provided a 31-day track of a single directed movement to the southwest for a distance of approximately $1,725 \mathrm{~km}$, at which point the tag detached. Its overall movement rate was around $55 \mathrm{~km} / \mathrm{d}(0.65 \mathrm{~m} / \mathrm{s})$.

The largest whale shark (WS-4, $11 \mathrm{~m}$ ) made repeated northeast-southeast movements, reaching a maximum distance of $620 \mathrm{~km}$ southeast of Darwin, on 3 October 2012, three weeks after tagging (moving a cumulative distance of $1,830 \mathrm{~km}$ at an overall rate of $67 \mathrm{~km} / \mathrm{d}$ ). It then returned almost directly to Darwin over a period of a week at a much faster overall rate of $98 \mathrm{~km} / \mathrm{d}$, and was detected within $50 \mathrm{~km}$ of the island on 12 and 13 October 2012, after which it began to move west.

The two floating tags (FL-1 and FL-2) drifted westwards to the open ocean with the South Equatorial Current for approximately $1,200 \mathrm{~km}$, then circled northwards into a eddy at about $4^{\circ} \mathrm{N}$ and $100^{\circ} \mathrm{W}$ (Figure 2). However, FL-1 reached the eddy in two weeks, traveling at an average speed of $78 \mathrm{~km} / \mathrm{d}$ (or $0.9 \mathrm{~m} / \mathrm{s}$ ), whereas FL-2 took two months to cover the same distance, at an average speed of $20.8 \mathrm{~km} / \mathrm{d}$ (or $0.25 \mathrm{~m} / \mathrm{s}$ ).

The floating tags provided multiple daily data packages, starting at midnight (Coordinated Universal Time (UTC) time) and ending within six hours (Figure 3). By contrast, the timing of the transmissions for the tags attached to sharks was at first generally from 12:00 pm to 12:00 am UTC, which corresponds to local daylight hours. However, there appeared to be considerable variation among individuals in the length of time spent at the surface. For example, packages for WS-1 were recorded by Argos very intermittently, with gaps of three or more days without a position location, whereas WS-2 provided positions on most days, excepting a three-day gap in early October. Argos recorded packages every day from WS-3. For each of these three tags, there was a clear change in pattern, when transmissions changed from their original timings to be daily and consistently between midnight and 05:00 am UTC, in the same fashion as the floating tags. The time at which this change in pattern occurred was the first indication that the tag has detached. By contrast, WS-4 was unusual in that the tag appeared to detach on October 26 2012, yet after apparently floating at the surface for over three weeks, on 17 November 2012 it changed once more, and transmitted at all times of the day. The ambiguity of this pattern may lead us to conclude either that the whale shark spent three weeks continuously at the surface, or that the tag detached and later became entangled with another organism or object.

The histograms of transmission quality over time show that, for the two floating tags, the quality of the transmissions was generally high, displaying a large proportion of class 2 and 3 transmissions over the entire track period (Figure 4). By contrast, for WS-1, 2 and 3, there was a clearly defined switch from a majority of poor detections (many As and Bs), to a sudden improvement in the same fashion as the floating tags. For all three tags, the date of this switch was consistent with the switch in transmission times (Figure 3). Again, WS-4 displays this switch, but reverts to poor quality detections after a period of three weeks. Thus, the data on transmission quality reflect the same patterns displayed by the transmission times.

The depth data from the SPLASH tag on WS-4 showed that, until 13 October 2012, the tag was in the top $100 \mathrm{~m}$ of the water column, and generally spent daytime hours close to or at the surface, while night hours were spent at an average depth of $50 \mathrm{~m}$. After 13 October 2012, there was a sudden switch, and the tag was constantly either at the surface, or between 0 and $10 \mathrm{~m}$. On 19 November 2012, there was another switch, and the tag began recording significant time spent below $20 \mathrm{~m}$, reaching a depth of up to $200 \mathrm{~m}$ (Figure 5).

Both of the floating tags showed very little variation in ambient temperature within a day, although both moved into warmer waters (from $22^{\circ} \mathrm{C}$ to $24^{\circ} \mathrm{C}$ ) as the track progressed (Figure 6). The remaining three SPOT tags (deployed on the whale sharks) displayed significant amounts of time spent in waters as cool as $12^{\circ} \mathrm{C}$ to $14^{\circ} \mathrm{C}$, indicating a variation in depth, followed by more constant temperature regimes once the tag apparently detached. During the first week of the track, WS-3 displayed particularly high temperatures of over $26^{\circ} \mathrm{C}$, along with a corresponding significant time spent at temperatures between $14^{\circ} \mathrm{C}$ and $16^{\circ} \mathrm{C}$. After the first week, the majority of time was spent between $22^{\circ} \mathrm{C}$ and $24^{\circ} \mathrm{C}$. After 6 October 2012 , WS-3 spent $100 \%$ of the time in the same temperature range of $24^{\circ} \mathrm{C}$ to $26^{\circ} \mathrm{C}$, which corresponds with sea surface temperatures at those locations and times.

\section{Discussion}

The tracks presented in this study suggest that whale sharks do not reside at Darwin, but rather that Darwin is a common location in their long-distance movements. With the exception of southern Baja California [6], Darwin is the only location where large, apparently gravid females make up most of the observed population. All three of the sexually mature, apparently pregnant females returned to 


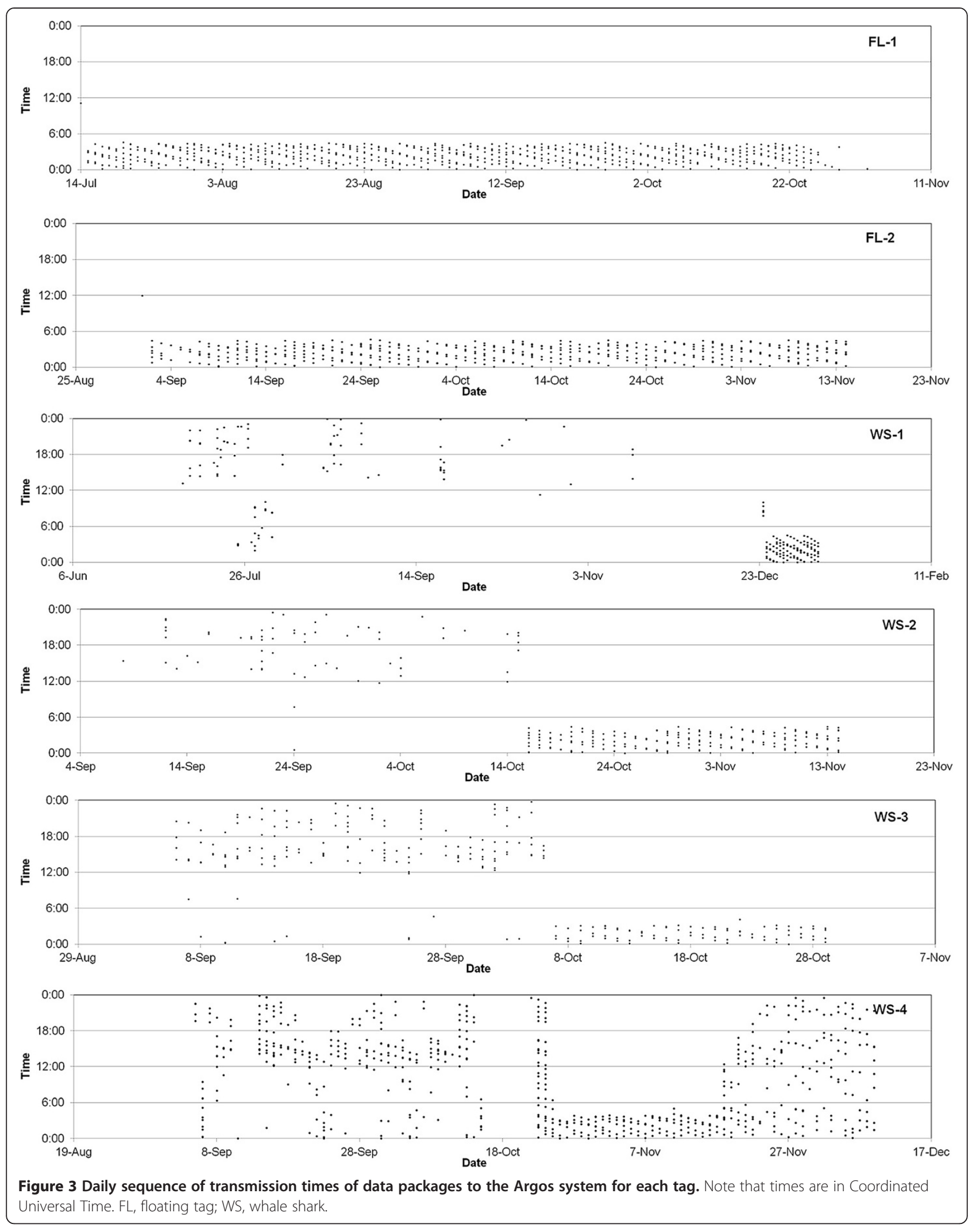



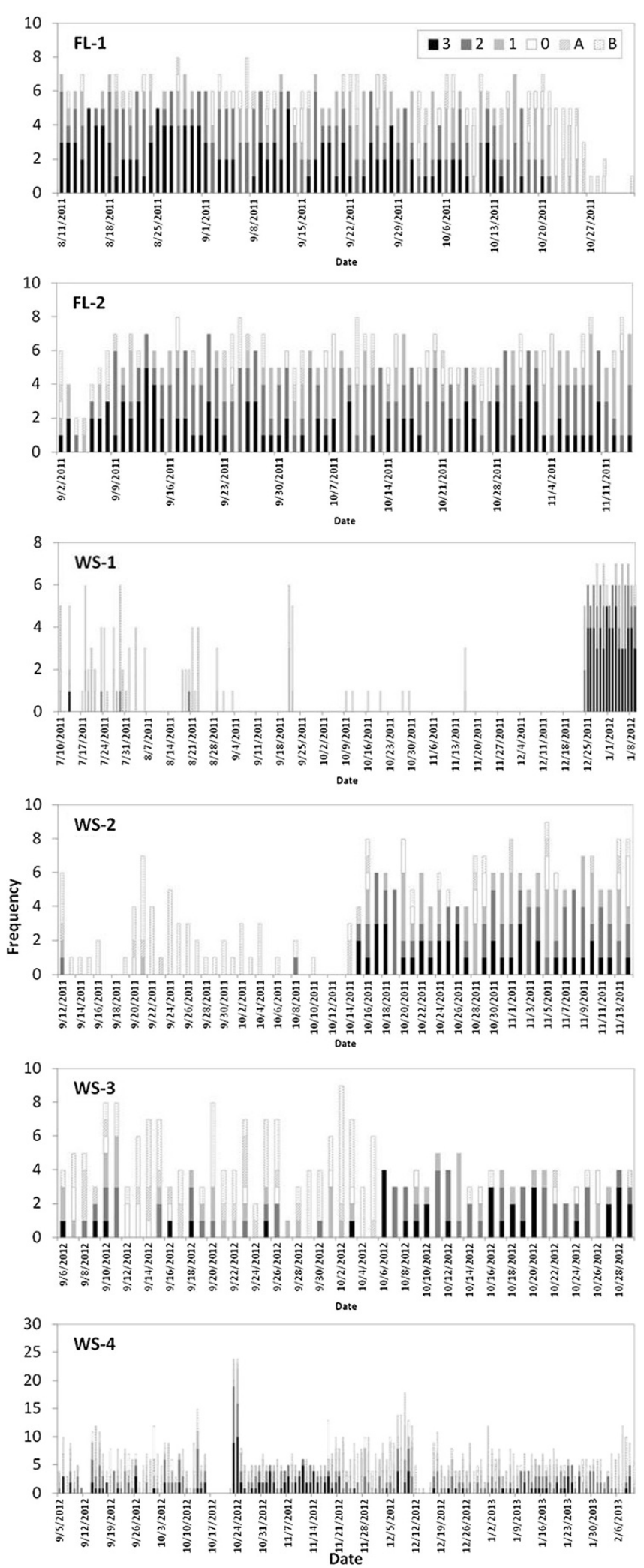

Figure 4 Histograms of daily quality of transmissions for each tag. Transmission quality ranging from $\mathbf{3}$ to $\mathbf{0}$ (highest to lowest quality, with increasing positional error estimate), then $\mathbf{A}$ and $\mathbf{B}$ (no positional error estimate). FL, floating tag; WS, whale shark. 


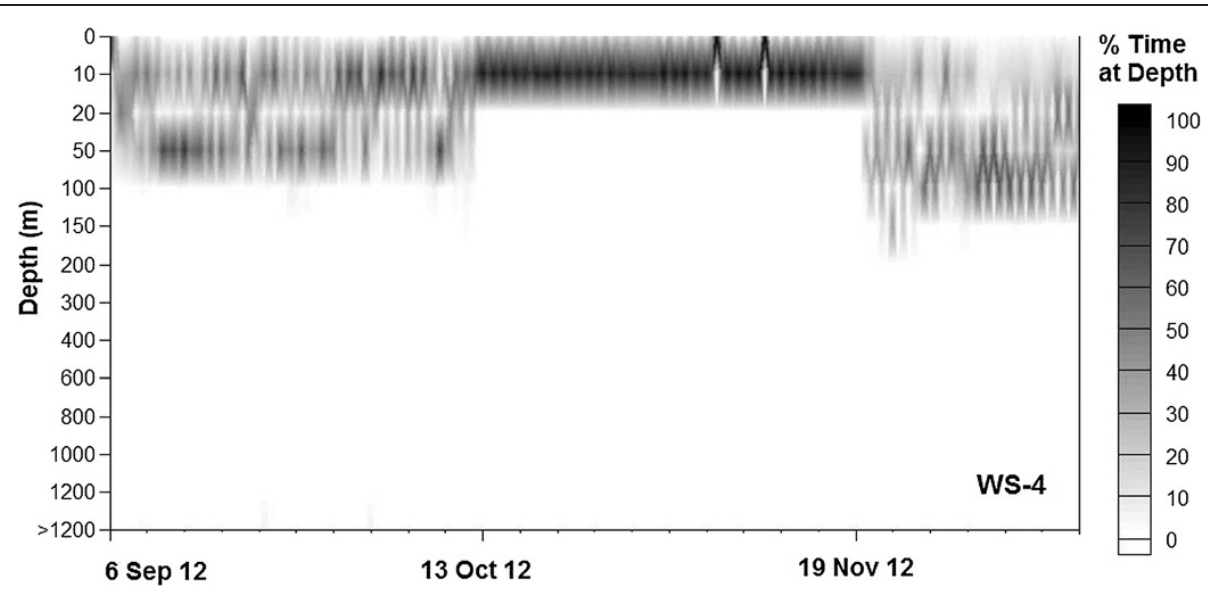

Figure 5 Time spent at depth for SPLASH tag\#120704 (WS-4), in 12-hour bins, starting and ending at 6 am and 6 pm local time (corresponding approximately with local dawn and dusk). WS, whale shark.
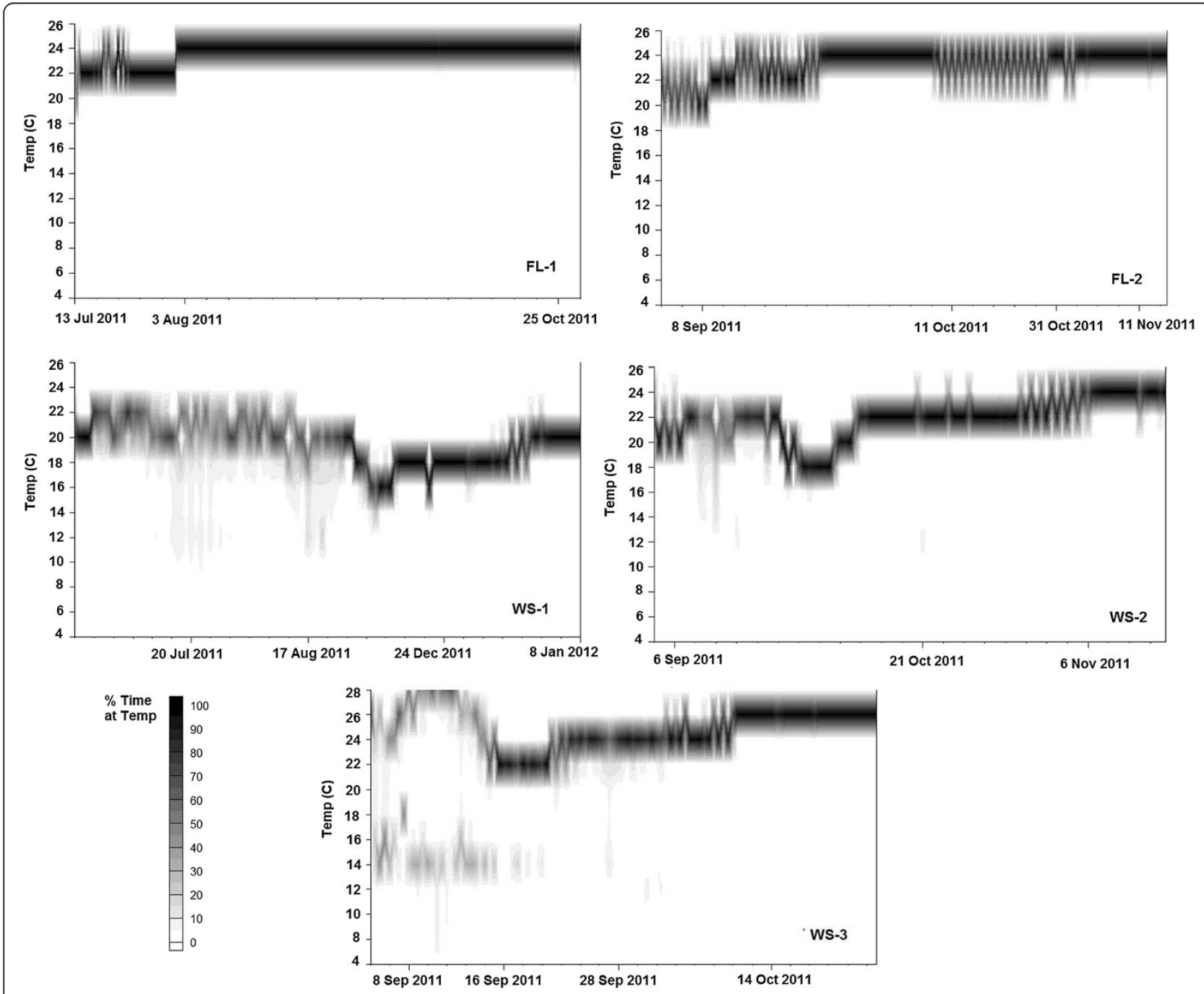

Figure 6 Time spent at temperature ranges for SPOT-5 tags, in 12-hour bins, starting and ending at 6 am and 6 pm local time (corresponding approximately with local dawn and dusk). Note that y-axis of temperature bins varies between tags. FL, floating tag; WS, whale shark. 
within $75 \mathrm{~km}$ of Darwin several weeks after tagging, and, although in all cases the track continued elsewhere, these make up the first published tracks of return movements. The only whale shark not to make a return movement was the immature female.

The track for WS-1 ended along the shelf break of northern Peru, corroborating the presence of whale sharks in Peru, where they have previously only been recorded anecdotally [25].

Our results show that, by using a combination of transmission times and qualities along with temperature or depth summaries, it is usually possible to determine when detachment occurred. We would expect to see a consistent pattern of daily transmissions beginning at midnight (UTC) and ending only a few hours later when the programmed daily allowance of transmissions has been reached. Similarly, we would expect the location quality to be higher from a floating tag than from one subjected to drag from a moving subject below the surface. The antenna would be submerged more often, and hence the salt water switch would turn off the signal transmission. If there is information on general ocean circulation patterns in the area, this also facilitates the process. Little support for passive diffusion by currents as a factor influencing whale shark distribution was found in the north eastern Indian Ocean, with swimming speeds up to three times greater than the maximum surface current velocities that whale sharks encountered [26].

We propose that future studies using towed satellite tags make explicit reference to the criteria used to determine detachment points. We chose to rank our criteria in order of simplicity, such that the first step is the creation of a simple scatterplot of detection times per day, obtained from the raw Argos log. When all transmissions occur during the first few hours after midnight each day for a prolonged period, this is a clear indication of a detached tag. Second, there is a break in the daily quality of locations with a greater proportion of high quality positions occurring when the tag has detached. Third, where depth data are not available, temperature histograms used in conjunction with sea surface temperature data from the study area can be used to show that the detached tag is permanently in the top layer of the water column. Finally, if the track follows the prevailing current, this may be used to validate the assumption that the tag has detached.

In most cases, all detachment criteria will coincide (Table 1). Our sample size was small (only two floater tags and four tags deployed on whale sharks), and in other instances there may be confounding effects of more variable currents and rough seas preventing floating tags from transmitting in such a regular fashion. However, this provides a rapid means of flagging potential detached tags without the need for any additional data besides the raw Argos logs.

When all the criteria do not coincide, such as with WS-4, it may be necessary to use prior knowledge of the subject species to make a judgment call. For example, we determined that it was unlikely a whale shark would remain at the surface constantly for a month, based on previously published information on whale shark diving behavior $[12,13]$. Rather, we assume that the tag detached and floated for a month, then become entangled with another organism. However, given the ambiguity in this case, we might consider presenting the entire track, but displaying where there is uncertainty so that readers can to come to their own conclusion.

The increasing literature on whale shark movement patterns provides us with more data for justifying track endpoints. For example, based on published information on diving behavior for whale sharks, the longest recorded track of a whale shark, travelling 13,000 km from the Gulf of California across the Pacific [6], has recently been questioned [7] due to the distance of around $10,000 \mathrm{~km}$ between the main portion of the track and the last few data points. Again, given what we can glean from the existing sample size of tagged whale sharks, it is unlikely that it would have travelled that distance over that time period without spending sufficient time at the surface for the satellites to pick up a transmission.

\section{Conclusion}

Whale sharks utilize Darwin's Arch for brief periods during large scale movements in the Eastern Tropical Pacific. All three of the mature, apparently pregnant females briefly returned close to Darwin (within $75 \mathrm{~km}$ ) after absences of one week to three months, before continuing their movements. The longest track (almost five months) ended off the shelf break of northern Peru. Darwin Island appears to serve as a waypoint for pregnant females on a larger scale migration between the coast of South American and the open ocean.

The data provided by floating tags is sufficiently distinct to be able to determine a detachment date. After detachment, daily transmissions are received in the hours following midnight (UTC), the location quality of the transmissions is consistently high, and temperature or depth summaries are consistent with surface records. Prior knowledge of subject behavior and local current patterns reinforces the ability to determine detachment date. In some cases, after a prolonged period of more than three or four weeks, the detection pattern may change, yet caution should be exercised in assuming that the tag is, after all, still attached. A period of rough seas might disturb this pattern briefly, and the tag becomes fouled or entangled over time. We suggest that where 
there is uncertainty about the nature of the track, this should be made explicit.

\section{Methods}

Whale sharks were tagged off Darwin Island, Galapagos at a location known as Darwin's Arch $\left(1.6725^{\circ},-91.989^{\circ}\right)$. At this site, a rocky platform at a depth of approximately $7 \mathrm{~m}$ drops almost vertically to over $30 \mathrm{~m}$ along a $300 \mathrm{~m}$ stretch. Although whale sharks may be sighted infrequently throughout the Galapagos Archipelago, Darwin's Arch has become an important site for dive tourism, partly due to the predictable occurrence of small numbers of whale sharks from June through November each year (coinciding with the cool season). Our research cruises were timed to coincide with the start, middle and end of the whale shark season. Tags were deployed in different months in 2011 (WS- 1 on 8 July, WS-2 on 8 September, FL-1 on 14 July, FL-2 on 1 September) and in 2012 (WS-3 on 5 September, WS-4 on 6 September).

Our search strategy consisted of two dive teams, each made up of a photographer, a tagger and a support diver. Both teams patrolled Darwin's Arch at the drop off, awaiting the arrival of whale sharks. Whale shark encounters ranged from none to five for each 40-minute dive. Due to strong currents and dive depth limitations, not every encounter resulted in a tagging attempt. We attached the tags to the sharks via $1.5 \mathrm{~m}$ tethers made from stainless steel cable and stainless steel darts. Tags were coated with a non-metal based antifouling paint prior to attachment. The tags were attached to the shark in front of or immediately behind the base of the first dorsal fin by use of a pneumatic spear gun. The total length of the sharks was estimated using laser photogrammetry [27], whereby a photo of the flank of the whale shark was taken using a camera with two laser pointers at a known distance apart (in this case, $50 \mathrm{~cm}$ ) and then the length between the fifth gill and first dorsal fin was scaled up to the total length of the shark $\left(\mathrm{r}^{2}=\right.$ 0.93) [27]. The gender of sharks was evident by the presence or absence of claspers as observed by the dive team in situ and, where possible, confirmed with photographic or video evidence.

All interactions with whale sharks were carried out in accordance with the University of California Davis Animal Care Protocol \#16022.

We used five position-determining satellite tags (SPOT-5; Wildlife Computers, Redmond, WA, USA), on both floating tags and the three pregnant females. We used one depth-recording tag (SPLASH; Wildlife Computers) on the immature female. The tags are encased in torpedo-shaped floating housings. They are unable to transmit while underwater, but are fitted with a wet-dry sensor that determines when they are on the surface, at which time they begin to transmit to Argos satellites. The positions of the tags are determined by Doppler shift in transmissions received by the satellite, and assigned a quality depending on the associated error of the position and the number of messages per pass. In cases where at least four messages are received, the quality class is numerical: 3 (error of the position < $250 \mathrm{~m}$ ), 2 (error of the position 250 to $500 \mathrm{~m}$ ), 1 (error of the position 500 to $1,500 \mathrm{~m}$ ), 0 (error of the position > $1500 \mathrm{~m}$. Where fewer than four messages are received, there is no error estimate and the quality is assigned a letter: A (three messages), B (one or two messages) [4]. The tags were programmed to transmit a maximum of 300 times a day, with no carryover to the next day if the allowance was not completed.

The SPLASH tag provided 12-hour summaries of depth, in the form of the percentage time spent at preprogrammed depth bins (ranging from 0 to $<1200 \mathrm{~m}$ ), while the SPOT- 5 tags provided similar summaries for time spent at different temperatures (see axes on Figure 6 for individual tag settings). For both tag types, the summaries were timed to coincide with local dawn and dusk.

For each tag, we created a scatter plot of transmission times for each day and a histogram of the quality of transmissions each day. The amount of time spent per day at different depth (SPLASH tag) and temperature (SPOT-5 tags) was also plotted for each tag, using DeltaGraph software (Red Rock Software, Inc., Salt Lake City, UT, USA).

We filtered the position locations obtained from the Argos system to remove duplicate messages, and to remove positions that implied sustained movements greater than $2 \mathrm{~m} / \mathrm{s}$. We used the remaining positions to create tracks using ArcMap 9.0 (ESRI, Redlands, CA, USA).

We obtained information from general ocean circulation patterns for the area from the literature [28]. At Darwin Island, the prevailing current is the South Equatorial Current, which flows to the west. To the north of this is the North Equatorial Countercurrent, which flows in the reverse direction.

\section{Competing interests}

The authors declare that they have no competing interests.

\section{Authors' contributions}

$\mathrm{AH}$ conceived the study, undertook the fieldwork, analyzed the data and wrote the manuscript. JG conceived the whale shark research project for the Galapagos Islands, obtained the funding, undertook the fieldwork and reviewed and approved the manuscript. EE, DA and CP undertook the fieldwork and reviewed and approved the manuscript. CP estimated the shark sizes. APK provided facilities for the analysis of the results, worked with $\mathrm{AH}$ on administration of contract, provided critical input in the analysis, and provided editorial input on the manuscript. All authors read and approved the final manuscript.

\section{Acknowledgements}

The whale shark research project for the Galapagos Islands was funded by the Blake, Kimberly and George Rapier Charitable Trust, by grants issued through Conservation International and The Galapagos Conservancy. Thanks to the Captain and Crew of the Queen Mabel. We wish to acknowledge the 
in-field support of Yasmania Llerena, Inti Keith, Gabriel Vazquez, Jules Paredes and Pelayo Salinas. The fieldwork was carried out under permits PC-37-11 and MAE-PNG/CDS-2012-0020 from the Galapagos National Park Service.

\section{Author details}

'Department Wildlife, Fish \& Conservation Biology, University of California Davis, One Shields Avenue, Davis, CA 95616, USA. ${ }^{2}$ Charles Darwin Foundation, Santa Cruz, Galapagos Islands, Ecuador. ${ }^{3}$ Galapagos National Park Service, Santa Cruz, Galapagos Islands, Ecuador. ${ }^{4}$ Turtle Island Restoration Network, 9255 Sir Francis Drake Boulevard, Olema, CA 94950, USA.

Received: 22 March 2013 Accepted: 3 July 2013

Published: 6 August 2013

\section{References}

1. Godley BJ, Blummenthal JM, Broderick AC, Coyne MS, Godfrey MH, Hawkes $L A$, Witt $M J$ : Satellite tracking of sea turtles: where have we been and where do we go next? Endang Species Res 2008, 4:3-22.

2. Hart KM, Hyrenbach KD: Satellite telemetry of marine megavertebrates: the coming of age of an experimental science. Endang Species Res 2009, 10:9-20.

3. Hammerschlag N, Gallagher AJ, Lazarre DM: A review of shark satellite tagging studies. J Exp Mar Biol Ecol 2011, 398:1-8.

4. Argos CLS: Argos User's Manual. Worldwide Tracking and Environmental Monitoring by Satellite. Ramonville Saint-Anne, France: CLS/Service Argos; 2007. Updated 2011

5. Priede IG: A basking shark (Cetorhinus maximus) tracked by satellite together with simultaneous remote sensing. Fish Res 1984, 2:201-206.

6. Eckert SA, Stewart BS: Telemetry and satellite tracking of whale sharks, Rhincodon typus, in the Sea of Cortez, Mexico, and the north Pacific Ocean. Env Biol Fish 2001, 60:299-308.

7. Sequeira AMM, Mellin C, Meekan MG, Sims DW, Bradshaw CJA: Inferred global connectivity of whale shark Rhincodon typus populations. J Fish Biol 2013, 82:367-389.

8. Klimley AP: Highly directional swimming by scalloped hammerhead sharks, Sphyrna lewini, and subsurface irradiance, temperature, bathymetry and geomagnetic field. Mar Biol 1993, 117:1-22

9. Hammerschlag N, Luo J, Irschick DJ, Ault JS: A comparison of spatial and movement patterns between sympatric predators: Bull sharks (Carcharhinus leucas) and Atlantic Tarpon (Megalops atlanticus). PLoS One 2012, 7(9):e45958.

10. Graham RT, Witt MJ, Castellanos DW, Remolina F, Maxwell S, Godley BJ, Hawkes LA: Satellite tracking of manta rays highlights challenges to their conservation. PLoS One 2012, 7(5):e36834.

11. Chen CT, Liu KM, Joung SJ: Preliminary report on Taiwan's whale shark fishery. Traffic Bull 1997, 17:53-57.

12. Graham RT, Roberts CM, Smart JCR: Diving behavior of whale sharks in relation to a predictable food pulse. J $R$ Soc Interf 2006, 3:109-116

13. Wilson SG, Polovina JJ, Stewart BS, Meekan MG: Movements of whale sharks (Rhincodon typus) tagged at Ningaloo Reef, Western Australia. Mar Biol 2001, 148:1157-1166.

14. Colman JG: A review of the biology and ecology of the whale shark. $J$ Fish Biol 1997, 51:1219-1234.

15. Heyman WD, Graham RT, Kjerfve B, Johannes RE: Whale sharks Rhincodon typus aggregate to feed on fish spawn in Belize. Mer Ecol Prog Ser 2001, 215:275-282.

16. De la Parra-Venegas R, Hueter R, Gonzalez Cano J, Tyminski J, Remolina JG, Maslanka M, Ormos A, Weigt L, Carlson B, Dove A: An unprecedented aggregation of whale sharks Rhincodon typus, in Mexican coastal waters of the Caribbean Sea. PLoS One 2011, 6(4):e18994.

17. Riley MJ, Hale MS, Harman A, Rees RG: Analysis of whale shark Rhincodon typus aggregations near South Ari Atoll, Maldives Archipelago. Aquat Biol 2010, 8:145-150

18. Norman BM, Stevens JD: Size and maturity of the whale shark (Rhincodon typus) at Ningaloo Reef, in Western Australia. Fish Res 2007, 84:81-86.

19. Ramirez-Macias D, Meekan M, De la Parra-Venegas R, Remolina-Suarez F, Trigo-Mendoza M, Vazquez-Juarez R: Patterns in composition, abundance and scarring of whale sharks Rhincodon typus near Holbox Island, Mexico. J Fish Biol 2012, 80:1401-1416.

20. Rowat $D$, Gore M: Regional scale horizontal and local scale vertical movements of whale sharks in the Indian Ocean off Seychelles. Fish Res 2007, 84:32-40.
21. Sleeman JC, Meekan MG, Fitzpatrick BJ, Steinberg CR, Ancel R, Bradshaw CJA: Oceanographic and atmospheric phenomena influence the abundance of whale sharks at Ningaloo Reef, Western Australia. J Exp Mar Biol Ecol 2010, 382:77-81.

22. Rowat $D$, Brooks KS: A review of the biology, fisheries and conservation of the whale shark Rhincodon typus. J Fish Biol 2012, 80:1019-1056.

23. Holmberg J, Norman B, Arzoumanian Z: Estimating population size, structure, and residency time for whale sharks Rhincodon typus through collaborative photo-identification. Endang Species Res 2009, 7:39-53.

24. Hearn A, Green J, Peñaherrera C, Acuña D, Espinoza E, Llerena Y, Klimley AP: Proyecto de investigacion de tiburones en la reserva marina de galapagos marcaje de tiburones ballena. Reporte final, 2011. Galapagos Islands, Ecuador: Galapagos National Park Service/Charles Darwin Foundation; 2011.

25. Ramirez P: Observaciones de tiburon ballena, Rhineodon typus, frente a Paita, Peru. Inf Prog Inst Mar Peru 1995, 16:23-25.

26. Meekan MG, Speed CW, Planes S, McLean C, Bradshaw CJA: Population monitoring for whale sharks (Rhincodon typus). Report prepared for the Australian Government Department of the Environment, Water, Heritage and the Arts. Australian Institute of Marine Science: Townsville, QLD; 2008.

27. Rohner CA, Richardson AJ, Marshall AD, Weeks SJ, Pierce SJ: How large is the world's largest fish? Measuring whale sharks Rhincodon typus with laser photogrammetry. J Fish Biol 2011, 78:378-385.

28. Kessler WS: The circulation of the eastern tropical pacific: a review. Prog Oceanog 2006, 69:181-217.

doi:10.1186/2050-3385-1-11

Cite this article as: Hearn et al: Simple criteria to determine detachment point of towed satellite tags provide first evidence of return migrations of whale sharks (Rhincodon typus) at the Galapagos Islands, Ecuador. Animal Biotelemetry 2013 1:11.

\section{Submit your next manuscript to BioMed Central and take full advantage of:}

- Convenient online submission

- Thorough peer review

- No space constraints or color figure charges

- Immediate publication on acceptance

- Inclusion in PubMed, CAS, Scopus and Google Scholar

- Research which is freely available for redistribution 